\title{
Acute hyperglycemia enhances oxidative stress and exacerbates myocardial infarction by activating nicotinamide adenine dinucleotide phosphate oxidase during reperfusion
}

\author{
Zequan Yang, MD, ${ }^{a}$ Victor E. Laubach, $\mathrm{PhD},{ }^{\mathrm{a}}$ Brent A. French, $\mathrm{PhD},{ }^{\mathrm{b}}$ and Irving L. Kron, $\mathrm{MD}^{\mathrm{a}}$
}

Objective: Acute hyperglycemia is independently associated with larger myocardial infarct size in both diabetic and nondiabetic patients. We hypothesized that the oxidative stress imposed by acute hyperglycemia contributes to the exacerbation of infarct size during reperfusion.

\begin{abstract}
Methods: C57BL/6 mice underwent 30 minutes of occlusion of the left anterior descending coronary artery followed by 60 minutes of reperfusion. Acute hyperglycemia was induced with an intraperitoneal injection of dextrose ( $2 \mathrm{~g} / \mathrm{kg}$ body weight) 30 minutes before left anterior descending occlusion. An antioxidant, $N$-2-mercaptopropionyl glycine, was injected intravenously 2 minutes before the onset of reperfusion at a dose of $20 \mathrm{mg} / \mathrm{kg}$. A nicotinamide adenine dinucleotide phosphate oxidase inhibitor, apocynin $(50 \mathrm{mg} / \mathrm{kg})$, was applied either before or after the induction of hyperglycemia.

Results: Blood glucose level before left anterior descending occlusion was $153 \pm 19 \mathrm{mg} / \mathrm{dL}$ in control mice and $444 \pm 26 \mathrm{mg} / \mathrm{dL}$ in hyperglycemic mice $(P<.05)$. Plasma lipid peroxidation product (malondialdehyde) was significantly increased in both control and hyperglycemic mice at 1 hour after reperfusion, and levels of malondialdehyde in hyperglycemic mice were higher than that in control mice $(3.38 \pm 0.21 \mathrm{vs} 2.33 \pm 0.12 \mu \mathrm{mol} / \mathrm{L} ; P<$ $.05) . N$-2-mercaptopropionyl glycine administered just before reperfusion significantly reduced malondialdehyde levels in both control and hyperglycemic mice $(1.21 \pm 0.06$ and $1.03 \pm 0.24 \mu \mathrm{mol} / \mathrm{L})$. Acute hyperglycemia increased infarct size (percent of risk region) from $34.0 \pm 2.7$ to $49.4 \pm 1.6(P<.05)$. $N$-2-mercaptopropionyl glycine reduced infarct size to $19.5 \pm 2.3$ in control mice and to $26.2 \pm 2.9$ in hyperglycemic mice. Apocynin also reduced malondialdehyde levels and infarct size in hyperglycemic mice if administered 5 minutes before injection of dextrose, but not before reperfusion.
\end{abstract}

Conclusion: Acute hyperglycemia enhances oxidative stress and exacerbates myocardial infarction in mice through activation of nicotinamide adenine dinucleotide phosphate oxidase.

Reperfusion injury after cardioplegic arrest exists even with optimal cardioprotective strategy. Hyperglycemia is commonly present in the perioperative period in patients undergoing cardiac surgery. ${ }^{1-3}$ Hyperglycemia during cardiopulmonary bypass is an independent risk factor for mortality and morbidity both in patients with diabetes mellitus and in those without. ${ }^{3}$ However, the significance of hyperglycemia in the nondiabetic patient undergoing cardiac surgery and the potential benefits of glucose-insulin-potassium infusion are still the subject of intense debate. ${ }^{1}$ An increasing body of clinical evidence has shown that acute hyperglycemia (or stress hyperglycemia) is independently associated with larger myocardial infarct size and impaired left ventricular function in both diabetic and nondiabetic patients. ${ }^{4,5}$

\footnotetext{
From the Departments of Surgery ${ }^{\mathrm{a}}$ and Biomedical Engineering, ${ }^{\mathrm{b}}$ University of Virginia Health System, Charlottesville, Va.

This study was funded by National Institutes of Health Grant R01 HL 058582 to B.A.F.

Received for publication April 28, 2008; revisions received July 29, 2008; accepted for publication Aug 31, 2008.

Address for reprints: Zequan Yang, MD, Department of Surgery, University of Virginia Health System, PO Box 801359, Charlottesville, VA 22908 (E-mail: zy6b@virginia.edu).

J Thorac Cardiovasc Surg 2009;137:723-9

$0022-5223 / \$ 36.00$

Copyright (C) 2009 by The American Association for Thoracic Surgery

doi:10.1016/j.jtcvs.2008.08.056
}

Acute hyperglycemia is common in patients with myocardial infarction (MI), even in the absence of a history of diabetes. In one recent study of 1664 patients with acute MI, more than $25 \%$ had acute hyperglycemia on admission, but more than $30 \%$ of these patients had no history of diabetes. ${ }^{6}$ Moreover, animal studies have shown that the size of the MI increases in response to elevations in blood glucose levels ${ }^{7}$ and that acute hyperglycemia counteracts the cardioprotective effects of ischemic and pharmacologic preconditioning. ${ }^{89}$ Although the hyperglycemic exacerbation of MI has become the subject of increasing research, little is known about the mechanisms underlying this phenomenon.

Acute hyperglycemia is known to decrease endothelial nitric oxide production, thus impairing normal vascular function, ${ }^{10-12}$ adversely affecting coronary microcirculation, ${ }^{13}$ and markedly attenuating signal transduction pathways critical to endogenous cardioprotective responses. ${ }^{8}$ A recent study shows that pharmacologic preconditioning against MI in the setting of acute hyperglycemia can be restored by $N$-acetylcysteine (a potent antioxidant), ${ }^{14}$ suggesting a possible role for oxidative stress in the acute hyperglycemic exacerbation of MI.

In the current study, acute hyperglycemia was created in mice by intraperitoneal injection of concentrated dextrose before the scheduled ischemia/reperfusion injury. 


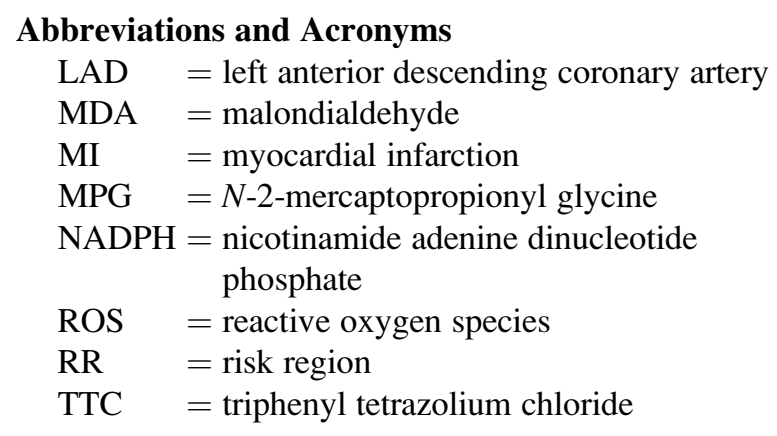

We hypothesized that the exacerbation of MI by acute hyperglycemia is due to oxidative stress resulting from the activation of nicotinamide adenine dinucleotide phosphate (NADPH) oxidase.

\section{MATERIALS AND METHODS}

This study conformed to the "Guide for the Care and Use of Laboratory Animals" published by the National Institutes of Health (NIH publication No. 85-23, revised 1985) and was conducted under protocols approved by the University of Virginia's Institutional Animal Care and Use Committee.

\section{Agents and Chemicals}

Triphenyl tetrazolium chloride (TTC), N-2-mercaptopropionyl glycine (MPG), and apocynin were purchased from Sigma-Aldrich (St Louis, Mo). Phthalo blue was purchased from Heucotech Ltd (Fairless Hills, Pa).

\section{Animals and Experimental Protocol \\ Sixty-three C57BL/6 mice (8-12 weeks old, purchased from Jackson Laboratories, Bar Harbor, Maine) were used in this study. Of these mice, 5 were used for dextrose dosing study to create acute hyperglycemia. An- other 3 mice underwent left thoracotomy as sham controls. The rest of the mice were assigned to 6 different groups and underwent 30 minutes of is- chemia and 60 minutes of reperfusion, as shown in Figure 1. Acute hyper- glycemia was induced by intraperitoneal injection of $20 \%$ dextrose 30 minutes before occlusion of the left anterior descending coronary artery (LAD) at a dose of $10 \mu \mathrm{L} / \mathrm{g}$ body weight (HG mice). In control mice, normal saline was given by intraperitoneal injection 30 minutes before LAD occlu- sion at a dose of $10 \mu \mathrm{L} / \mathrm{g}$ body weight. In MPG-treated mice, MPG (10 mg/ $\mathrm{mL}$ in phosphate-buffered saline solution) was administered 2 minutes be- fore reperfusion by intravenous injection at a dose of $2 \mu \mathrm{L} / \mathrm{g}$. In apocynin- treated mice, apocynin (APO; $5 \mathrm{mg} / \mathrm{mL}$ in $5 \%$ ethanol) was administered at a dose of $2 \mu \mathrm{L} / \mathrm{g}$ either intravenously 5 minutes before reperfusion in $\mathrm{HG}+\mathrm{APO}$ mice or intraperitoneally 5 minutes before induction of hypergly- cemia in APO+HG mice (Figure 1).}

\section{Myocardial Ischemia/Reperfusion Injury and Measurement of Infarct Size}

Mice were subjected to 30 minutes of coronary occlusion followed by 60 minutes of reperfusion and then humanely killed to evaluate myocardial infarct by TTC-phthalo blue staining. A standard protocol was used as detailed previously. ${ }^{15,16}$ In brief, mice were anesthetized with sodium pentobarbital $(100 \mathrm{mg} / \mathrm{kg}$ ip) and orally intubated. Artificial respiration was maintained with an inspired oxygen fraction of $0.80,100$ strokes per minute, and a $1.0-$ to $1.5-\mathrm{mL}$ stroke volume. The heart was exposed through a left thoracotomy, and coronary artery occlusion was achieved by passing a suture beneath the LAD and tightening over a piece of polyethylene-60 tubing for 30 minutes. Reperfusion was induced by removal of the polyethylene-60 tubing. The electrocardiogram was monitored perioperatively with PowerLab instrumentation (ADInstruments, Colorado Springs, Colo). The mice were humanely killed 60 minutes after reperfusion, and the hearts were cannulated through the ascending aorta for perfusion with 3 to $4 \mathrm{~mL}$ of $1.0 \%$ TTC. The LAD was then reoccluded with the same suture used for coronary occlusion before $10 \%$ phthalo blue perfusion to determine risk region (RR). The left ventricle was then cut into 5 to 7 transverse slices that were weighed and digitally photographed to determine infarct size as a percent of RR. Reperfusion for 60 minutes is selected because the infarct size appears homogeneous at that time and does not become larger with longer reperfusion periods. ${ }^{17}$

\section{Measurement of Plasma Malondialdehyde (MDA)}

At the end of 1 hour of reperfusion, blood was collected by puncturing the right ventricle and plasma was obtained after centrifuging the blood at $500 \mathrm{~g}$ for 8 minutes. Malondialdehyde (MDA) was measured with a commercial assay kit (Cayman Chemical Company, Ann Arbor, Mich).

\section{Statistical Analysis}

All data are presented as the mean \pm standard error of the mean. Peri-ischemic heart rate changes were analyzed by a repeated-measures analysis of variance followed by Bonferroni pairwise comparisons. All other data were compared by 1-way analysis of variance followed by a $t$ test for unpaired data with Bonferroni correction.

\section{RESULTS \\ Perioperative Heart Rate Changes}

Table 1 shows changes in heart rate before, during, and after LAD occlusion. Heart rate was increased significantly after LAD occlusion and remained tachycardiac until early reperfusion. There was no significant difference in heart rate between control and treated mice.

\section{Acute Hyperglycemia in Mice}

A preliminary dose range study conducted with a conventional glucose meter (iTest; Auto Control Medical Inc, Pointe-Claire, Canada) indicated that a single bolus injection of $20 \%$ dextrose $(10 \mu \mathrm{L} / \mathrm{g}$ or $2 \mathrm{~g}$ dextrose per kilogram body weight) sufficed to achieve transient blood glucose levels between 400 and $500 \mathrm{mg} / \mathrm{dL}$. A time course of blood glucose levels was then evaluated at this dose in a group of $5 \mathrm{C} 57 \mathrm{BL} /$ $6 \mathrm{~J}$ mice. Before injection, blood glucose in unfasted mice ranged from 117 to $150 \mathrm{mg} / \mathrm{dL}$ (mean, $129 \pm 8 \mathrm{mg} / \mathrm{dL}$ ). After injection, blood glucose increased rapidly to a peak at 20 minutes after injection of $442 \pm 48 \mathrm{mg} / \mathrm{dL}$, and then gradually declined while retaining mean levels of over $400 \mathrm{mg} / \mathrm{dL}$ for a period of 20 minutes (Figure 2). Blood glucose returned to baseline 2 hours after dextrose injection. Table 1 shows the blood glucose levels before LAD occlusion in all of the experimental groups, demonstrating that the hyperglycemic mice had significantly higher blood glucose levels than the other groups.

\section{Acute Hyperglycemia Enhances Oxidative Stress and Exacerbates MI}

Four groups of mice (Figure 1, top 4 groups) underwent 30 minutes of LAD occlusion followed by 60 minutes of 


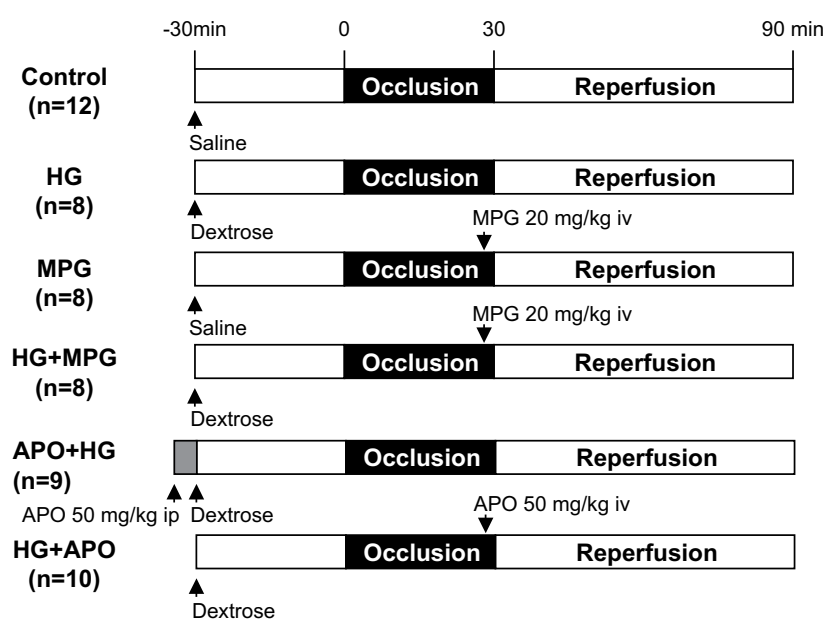

FIGURE 1. Study groups and experiment protocols. $H G$, Hyperglycemia; $M P G, N$-2-mercaptopropionyl glycine; $A P O$, apocynin.

reperfusion, and an additional sham group underwent thoracotomy without LAD occlusion. A potent antioxidant, MPG, was administered in MPG-treated groups at a dose of $20 \mathrm{mg} / \mathrm{kg} 2$ minutes before reperfusion. The mean blood glucose levels before LAD occlusion were $135 \pm 19 \mathrm{mg}$ / $\mathrm{dL}$ in control or $124 \pm 13 \mathrm{mg} / \mathrm{dL}$ in MPG-treated (MPG group) and $444 \pm 26 \mathrm{mg} / \mathrm{dL}$ in untreated hyperglycemic mice $(P<.05$, Table 1$)$. In control mice, plasma MDA was significantly increased during reperfusion compared with sham-operated mice $(2.33 \pm 0.12$ vs $0.71 \pm 0.05$ $\mu \mathrm{mol} / \mathrm{L} ; P<.05)$. Acute hyperglycemia further increased plasma MDA to $3.38 \pm 0.21 \mu \mathrm{mol} / \mathrm{L}(P<.05$ vs control or sham). Treatment with MPG significantly reduced plasma MDA in both control and hyperglycemic mice to $1.21 \pm 0.24 \mu \mathrm{mol} / \mathrm{L}$ and $1.03 \pm 0.06 \mu \mathrm{mul} / \mathrm{L}$, respectively $(P<.05$ vs either MPG or hyperglycemic groups, Figure 3$)$. Correspondingly, myocardial infarct size was enhanced by acute hyperglycemia. There were no statistical differences in RR size (percent of left ventricle) among the 4 groups (control, $42.7 \pm 1.7$; HG, $41.6 \pm 1.3$; MPG, $37.9 \pm 1.8$; HG+MPG: $38.9 \pm 1.5$ ). In control mice, infarct size

TABLE 1. Blood glucose levels before LAD occlusion and perioperative heart rates

\begin{tabular}{lcccc}
\hline & & \multicolumn{3}{c}{ Heart rate (beats/min) } \\
\cline { 3 - 5 } Groups & $\begin{array}{c}\text { Blood } \\
\text { glucose (mg/dL) }\end{array}$ & $\begin{array}{c}\text { Before } \\
\text { occlusion }\end{array}$ & $\begin{array}{c}\text { During } \\
\text { occlusion }\end{array}$ & Reperfusion \\
\hline Control & $153 \pm 19$ & $406 \pm 14$ & $443 \pm 9 \dagger$ & $445 \pm 10 \dagger$ \\
HG & $444 \pm 26^{*}$ & $407 \pm 15$ & $466 \pm 18 \dagger$ & $448 \pm 20$ \\
MPG & $124 \pm 13$ & $408 \pm 12$ & $458 \pm 11 \dagger$ & $428 \pm 10$ \\
HG+MPG & $480 \pm 21^{*}$ & $404 \pm 6$ & $453 \pm 16 \dagger$ & $445 \pm 13$ \\
HG+APO & $422 \pm 24^{*}$ & $393 \pm 9$ & $451 \pm 12 \dagger$ & $472 \pm 15 \dagger$ \\
APO + HG & $496 \pm 16^{*}$ & $395 \pm 12$ & $439 \pm 7 \dagger$ & $430 \pm 7 \dagger$ \\
\hline$H G$, Hyperglycemia; $M P G, N-2-$ mercaptopropionyl glycine; $A P O$, apocynin. $* P<.05$ \\
vs control $\dagger P<.05$ vs before occlusion.
\end{tabular}

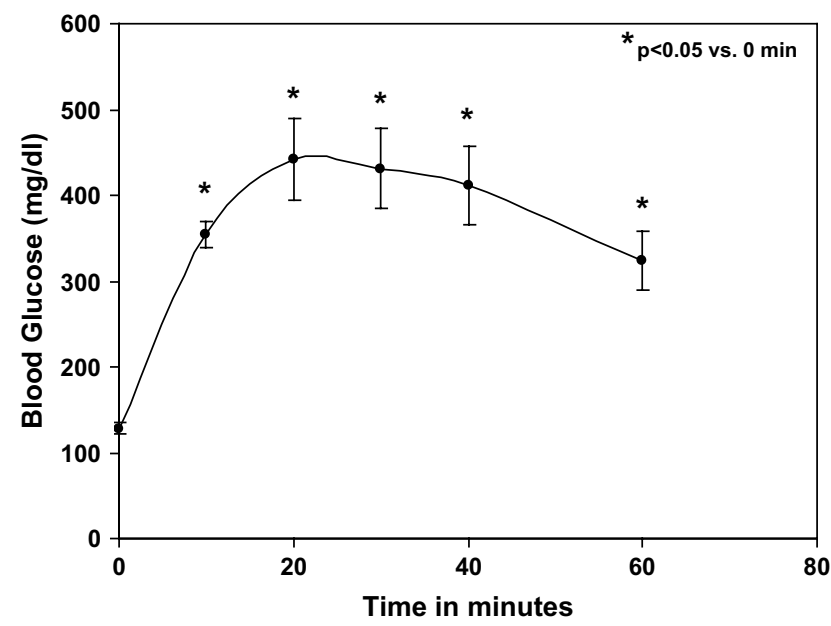

FIGURE 2. Time course of blood glucose levels after single ip injection of $20 \%$ dextrose $\left(10 \mu \mathrm{L} / \mathrm{g}\right.$ body weight). ${ }^{*} P<.05$ vs baseline (time 0 ).

(percent of RR) was $34.0 \pm 2.7$. Infarct size in $\mathrm{HG}$ mice increased by $45 \%$ to $49.4 \pm 1.6(P<.05$ vs control). Administration of MPG (MPG group) reduced infarct size to $19.5 \pm 2.3$ (43\% reduction from control). Administration of MPG to HG+MPG mice reduced infarct size to $30.0 \pm$ 4.3 , a $39 \%$ reduction $(P<.05$ vs HG mice, Figures 4 and 5).

\section{NADPH Oxidase Contributes to Acute} Hyperglycemic Exacerbation of MI

Apocynin, a specific NADPH oxidase inhibitor, was administered at a bolus dose of $50 \mathrm{mg} / \mathrm{kg}$ body weight either shortly before the onset of reperfusion intravenously (HG+APO) or before induction of hyperglycemia intraperitoneally (APO+HG, Figure 1). LAD ligation caused comparable RR in apocynin-treated mice as with other groups $(\mathrm{APO}+\mathrm{HG}, 37.2 \pm 1.4 ; \mathrm{HG}+\mathrm{APO}, 39.3 \pm 2.5 ; P=\mathrm{NS}$ vs control or HG group). Administration of apocynin before

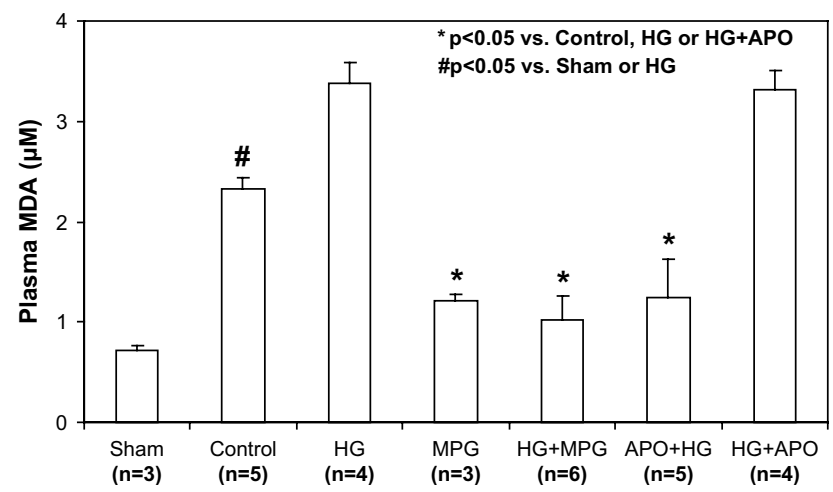

FIGURE 3. Plasma levels of malondialdehyde $(M D A)$ after 30 minutes of LAD occlusion and after 60 minutes of reperfusion. ${ }^{*} P<.05$ vs control, $\mathrm{HG}$, or HG+APO; $\# P<0.05$ vs sham or HG. $H G$, Hyperglycemia; $M P G$, $\mathrm{N}$-2-mercaptopropionyl glycine; $A P O$, apocynin. 


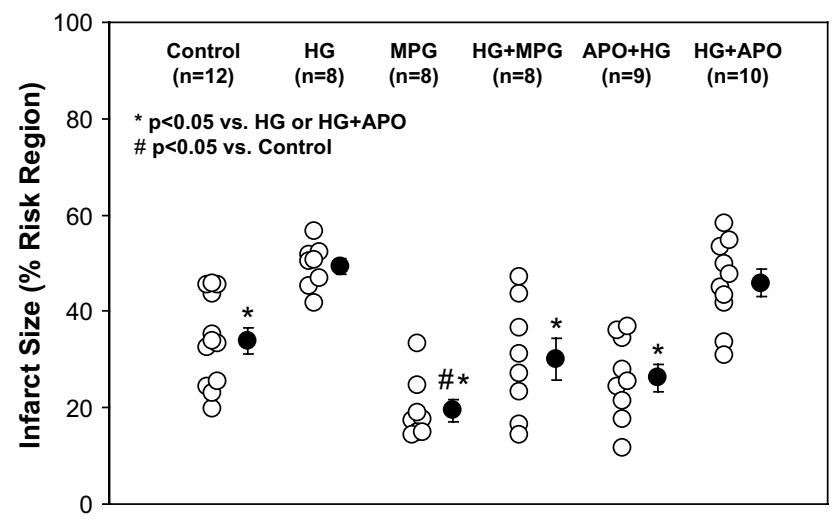

FIGURE 4. Myocardial infarct size after 30 minutes of LAD occlusion and 60 minutes of reperfusion. Acute hyperglycemia exacerbates infarct size. The hyperglycemic exacerbation of infarct size was completely abrogated by MPG administered at reperfusion or apocynin administered before hyperglycemia. $* P<.05$ vs HG or HG+APO; $\# P<.05$ vs control. $H G$, Hyperglycemia; $M P G, N$-2-mercaptopropionyl glycine; $A P O$, apocynin.

reperfusion ( $\mathrm{HG}+\mathrm{APO})$ had no effect on plasma MDA levels (3.32 $\pm 0.18 \mu \mathrm{mol} / \mathrm{L} ; P=$ not significant $[\mathrm{NS}]$ vs HG group) and correspondingly had no effect on infarct size of hyperglycemic mice $(45.9 \pm 2.8 ; P=\mathrm{NS}$ vs HG group; $P<.05$ vs control; Figures 3 to 5). However, administration of apocynin before the induction of hyperglycemia (APO+HG) significantly reduced MDA levels to $1.25 \pm 0.46 \mu \mathrm{mol} / \mathrm{L}(P<$ .05 vs HG or HG+APO) and abrogated the hyperglycemiainduced infarct expansion and significantly reduced infarct size to $26.2 \pm 2.9(P<.05$ vs HG: $P=\mathrm{NS}$ vs control; Figures 3 to 5).

\section{Correlation Between Plasma MDA Level and Myocardial Infarct Size}

By pooling the data from all 6 groups of mice, we found a strong correlation between MDA levels and myocardial infarct size 1 hour after reperfusion, $R^{2}=0.62$ (Figure 6).

\section{DISCUSSION}

Through administration of concentrated dextrose, acute hyperglycemia was created in nondiabetic mice. Acute hyperglycemia significantly increases the production of reactive oxygen species (ROS) during reperfusion as characterized by lipid peroxidation products (MDA) in plasma and thereby exacerbates myocardial infarct size in mice. The efficacy of MPG in reducing infarct size in hyperglycemic mice when administered only minutes before reperfusion demonstrates that oxidative stress contributes importantly to the hyperglycemic exacerbation of infarct size. MPG is a potent ROS scavenger and thus acts on the end products (ROS) of oxidative stress. Apocynin, a selective NADPH oxidase inhibitor, similarly inhibited oxidative stress and protected the heart against the hyperglycemic exacerbation of infarct size, but only when it was applied before the hyperglycemic insults, indicating that the hyperglycemic oxidative stress involves NADPH oxidase. Taken together, the results indicate that acute hyperglycemia induced in nondiabetic mice shortly before myocardial ischemia significantly increases oxidative stress and exacerbates $\mathrm{MI}$ in mice through the activation of NADPH oxidase.

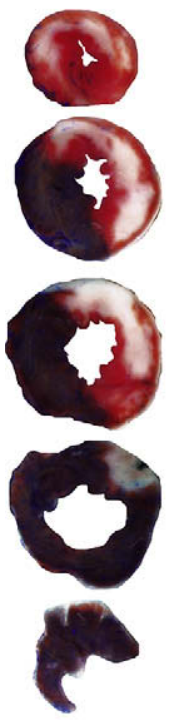

Control
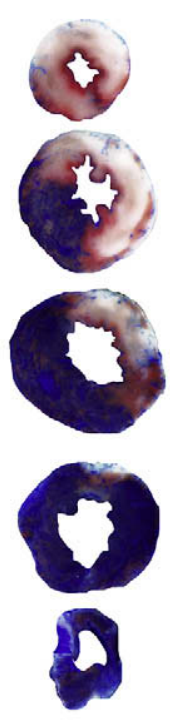

HG
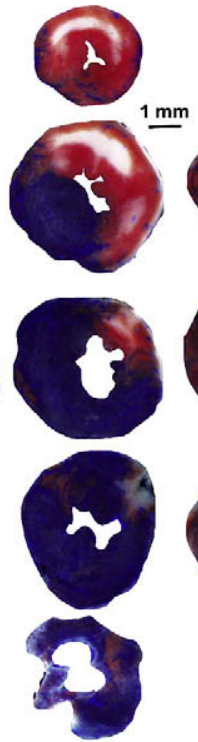

MPG

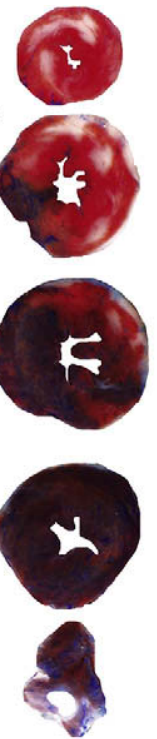

HG+MPG

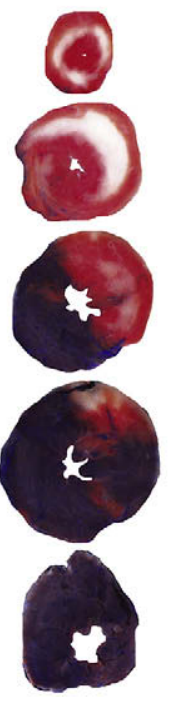

APO+HG

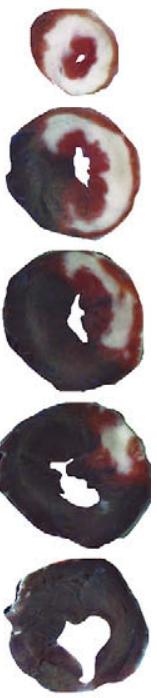

HG+APO

FIGURE 5. TTC- and phthalo blue-stained, short-axis tissue sections of left ventricles from representative mice from the 6 groups summarized in Figures 1 and 4. Blue areas are nonischemic tissue, yellowish white areas are infarcted tissue, and red areas represent salvaged (viable) tissue within the previously ischemic myocardium (risk region). 


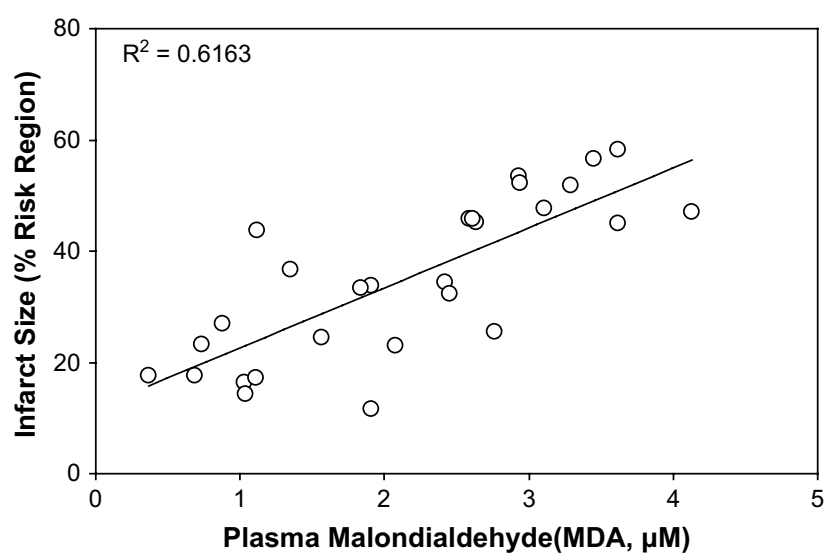

FIGURE 6. Correaltion between plasma MDA levels and myocardial infarct size by pooling the data from different groups. $R^{2}=0.62$.

Compelling evidence has shown that acute (or stress) hyperglycemia is an independent predictor of cardiovascular morbidity and mortality, independent of diabetes. ${ }^{3,18-20}$ Stress hyperglycemia shares many properties with hyperglycemia associated with type 2 diabetes, including increased oxidative stress, ${ }^{21-24}$ inflammation, ${ }^{25-28}$ and activation of stress-responsive kinase. ${ }^{20,26}$ Infarcts are usually larger in patients with stress or diabetes-related hyperglycemia, ${ }^{4,5,20,29}$ and animals with acute hyperglycemia sustain dramatically larger infarcts after experimental ischemia/ reperfusion than do euglycemic controls. ${ }^{7-9}$ Increased sensitivity to ischemia/reperfusion injury and more severe myocardial damage is one reason for the poor prognosis of patients having acute MI with stress hyperglycemia.

Although the mechanisms underlying acute or stress hyperglycemia may differ between patients and animal models, ${ }^{8,29}$ hyperglycemia has proven to be an independent risk factor for larger infarct size, ${ }^{4,5,7,8}$ and this hyperglycemic infarct exacerbation is not related to increased osmolality. ${ }^{7}$ To simulate the stress hyperglycemia seen in human patients, we similarly induced acute hyperglycemia in mice in the current study by intraperitoneal injection of concentrated dextrose. Sustained hyperglycemia ensued lasting over 30 minutes. LAD occlusion and reperfusion were performed during this period of hyperglycemia. Blood glucose levels were 3 -fold greater in hyperglycemic mice than in nonhyperglycemic mice. There was no difference in preoperative heart rate between hyperglycemic and nonhyperglycemic mice (Table 1). Myocardial ischemia and reperfusion induced oxidative stress that was documented after reperfusion. Acute hyperglycemia exacerbated this oxidative stress. Correspondingly, a significantly larger infarct size was found in hyperglycemic mice. This oxidative stress is positively correlated with myocardial infarct size $\left(R^{2}=0.62\right.$; Figure 6). An ROS scavenger, MPG, significantly reduced oxidative stress in both control and hyperglycemic mice and completely abrogated the hyperglycemic exacerbation of infarct size (Figures 3 to 5). To further define the source of the ROS responsible for the hyperglycemic exacerbation of infarct size, we applied a selective inhibitor of NADPH oxidase $^{30}$ (apocynin) to hyperglycemic mice. Apocynin proved to be as effective as MPG in completely abrogating the hyperglycemic oxidative stress and abolishing the hyperglycemic exacerbation of infarct size, provided it was administered before the induction of hyperglycemia. However, the cardioprotective effect of apocynin was lost when its application was delayed until after the induction of hyperglycemia (Figures 4 and 5).

Myocardial ischemia/reperfusion injury is also associated with oxidative stress in the nondiabetic subjects, as shown in the current study (Figure 3) and others. ${ }^{31,32}$ However, the role of ROS scavenger or NADPH inhibition in reducing MI remains controversial. ${ }^{33}$ Acute hyperglycemic exacerbation of myocardial ischemia/reperfusion injury has been documented in both clinical and animal studies, but the role of antioxidant therapy in this setting is lacking.

It is widely known that acute or stress hyperglycemia is associated with oxidative stress and inflammatory responses. ${ }^{10,21,23,24,26-28}$ The degree of oxidative stress correlates most closely with acute, not chronic, glucose fluctuations. ${ }^{24}$ Oxidative stress is defined in general as excess formation and/or insufficient removal of highly reactive molecules such as ROS and reactive nitrogen species. There are multiple potential sources of oxidative stress during hyperglycemia, including nonenzymatic, enzymatic, and mitochondrial sources. ${ }^{34}$ Nonenzymatic sources of oxidative stress originate from auto-oxidation of glucose or formation of advanced glycation end products. Enzymatic sources for the augmented generation of oxidative stress during hyperglycemia include nitric oxide synthase, NADPH oxidase, and xanthine oxidase. The mitochondrial respiratory chain is another potential source of oxidative stress in this setting. Although not fully understood, evidence is mounting to suggest that NADPH oxidase plays an important role in mediating acute hyperglycemic oxidative stress. ${ }^{23,27,34}$

In the current study, acute hyperglycemia-induced oxidative stress was clearly defined during reperfusion, and this oxidative stress, as well as the exacerbation in infarct size, was completely abolished with the use of a potent ROS scavenger or NADPH oxidase inhibitor. Interestingly, neither MPG nor apocynin could reduce infarct size in hyperglycemic mice back to the size found in MPG-treated euglycemic mice (Figure 4). This may reflect the deleterious effects of hyperglycemia on the endogenous defense system of cardiomyocytes, which makes them sensitive to ischemic injury. ${ }^{7,8,20}$ Thus antioxidant therapy appears to abrogate the exacerbation of reperfusion injury, but not ischemic injury.

Apocynin inhibits NADPH oxidase by acting as an irreversible inhibitor of the $\mathrm{p} 47^{\text {phox }}$ subunit. Apocynin prevents the translocation of cytosolic $\mathrm{p} 47^{\text {phox }}$ to Nox 2 in the membrane of leukocytes, monocytes, and endothelial cells. ${ }^{35-38}$ 
However, the compound requires activation by myeloperoxidase and/or $\mathrm{H}_{2} \mathrm{O}_{2}{ }^{38}$ to be effective. For this reason, the inhibitory action of the compound appears to be most effective in leukocytes and then only after a lag period..$^{37,38}$ Although the current experiment did not explore the possible cellular sources of oxidative stress, an increasing body of evidence indicates that acute or stress hyperglycemia activates leukocytes that mediate the oxidative stress and inflammatory responses. ${ }^{5,23,26}$ The cardioprotective effect of apocynin against the hyperglycemic exacerbation of infarct size is thus probably due to its action on the NADPH oxidases in leukocytes.

In the current experiments, the antioxidant and cardioprotective effects of apocynin against the hyperglycemic exacerbation of infarct size disappeared when it was administered just before reperfusion. The reason for this may be 2-fold: (1) acute hyperglycemia caused the translocation of $\mathrm{p} 47^{\text {phox }}$ and activation of NADPH oxidase before the administration of apocynin and (2) the lag time required for activation of the compound made it less effective against hyperglycemia-induced $\mathrm{p} 47^{\text {phox }}$ translocation. Treatment with apocynin before the induction of hyperglycemia in the "APO+HG" protocol provides adequate lag time for the activation of apocynin, thus enabling it to be effective in the inhibition of NADPH oxidase.

\section{Significance and Limitation of the Study}

The present study clearly shows that acute hyperglycemia enhances oxidative stress and exacerbates MI. The cardioprotective effect of MPG is manifest even when the compound is given at the time of reperfusion. This has important clinical implications because it demonstrates that it may be possible to intervene with antioxidants to reduce infarct size in cardiac patients undergoing cardiopulmonary bypass or in medical patients with acute MI undergoing percutaneous coronary intervention or thrombolysis by the simple administration of a potent antioxidant. Although NADPH oxidase plays a critical role in hyperglycemia-induced oxidative stress, the clinical application of inhibitor of NADPH oxidase is not practical inasmuch as it has to be used before the onset of hyperglycemia. However, further experiments are needed to define its role when it is administered before or early during ischemia.

\section{CONCLUSION}

The current study indicates that acute hyperglycemia enhances oxidative stress during reperfusion, which in turn exacerbates myocardial infarct size in nondiabetic mice. Potent antioxidants can protect the heart against the hyperglycemic exacerbation of infarct size. The efficacy of apocynin indicates that hyperglycemia-induced oxidative stress is mediated by the activation of NADPH oxidase. Finally, this study provides direct evidence showing that the deleterious effects of hyperglycemia on infarct size can be completely reversed in a practical and clinically relevant manner.

\section{References}

1. Lazar HL. Hyperglycemia during cardiac surgery. J Thorac Cardiovasc Surg. 2006;131:11-3.

2. Quinn DW, Pagano D, Bonser RS, Rooney SJ, Graham TR, Wilson IC, et al. Improved myocardial protection during coronary artery surgery with glucose-insulin-potassium: a randomized controlled trial. J Thorac Cardiovasc Surg. 2006; 131:34-42.

3. Doenst T, Wijeysundera D, Karkouti K, Zechner C, Maganti M, Rao V, et al. Hyperglycemia during cardiopulmonary bypass is an independent risk factor for mortality in patients undergoing cardiac surgery. $J$ Thorac Cardiovasc Surg. 2005;130:1144.

4. Ishihara M, Inoue I, Kawagoe T, Shimatani Y, Kurisu S, Nishioka K, et al. Impact of acute hyperglycemia on left ventricular function after reperfusion therapy in patients with a first anterior wall acute myocardial infarction. Am Heart J. 2003;146:674-8.

5. Marfella R, Siniscalchi M, Esposito K, Sellitto A, De Fanis U, Romano C, et al. Effects of stress hyperglycemia on acute myocardial infarction: role of inflammatory immune process in functional cardiac outcome. Diabetes Care. 2003;26: 3129-35.

6. Wahab NN, Cowden EA, Pearce NJ, Gardner MJ, Merry H, Cox JL, Investigators ICONS. Is blood glucose an independent predictor of mortality in acute myocardial infarction in the thrombolytic era? J Am Coll Cardiol. 2002; 40:1748-54.

7. Kersten JR, Toller WG, Gross ER, Pagel PS, Warltier DC. Diabetes abolishes ischemic preconditioning: role of glucose, insulin, and osmolality. Am J Physiol Heart Circ Physiol. 2000;278:H1218-24.

8. Kersten JR, Schmeling TJ, Orth KG, Pagel PS, Warltier DC. Acute hyperglycemia abolishes ischemic preconditioning in vivo. Am J Physiol. 1998;275:H721-5.

9. Kersten JR, Montgomery MW, Ghassemi T, Gross ER, Toller WG, Pagel PS, et al. Diabetes and hyperglycemia impair activation of mitochondrial K(ATP) channels. Am J Physiol Heart Circ Physiol. 2001;280:H1744-50.

10. Giugliano D, Marfella R, Coppola L, Verrazzo G, Acampora R, Giunta R, et al. Vascular effects of acute hyperglycemia in humans are reversed by L-arginine. Evidence for reduced availability of nitric oxide during hyperglycemia. Circulation. 1997;95:1783-90.

11. Bohlen HG, Nase GP. Arteriolar nitric oxide concentration is decreased during hyperglycemia-induced betaII PKC activation. Am J Physiol Heart Circ Physiol. 2001;280:H621-7.

12. Beckman JA, Goldfine AB, Gordon MB, Garrett LA, Creager MA. Inhibition of protein kinase Cbeta prevents impaired endothelium-dependent vasodilation caused by hyperglycemia in humans.[see comment]. Circ Res. 2002;90:107-11.

13. Fujimoto K, Hozumi T, Watanabe H, Tokai K, Shimada K, Yoshiyama M, et al. Acute hyperglycemia induced by oral glucose loading suppresses coronary microcirculation on transthoracic Doppler echocardiography in healthy young adults. Echocardiography. 2006;23:829-34.

14. Kehl F, Krolikowski JG, Weihrauch D, Pagel PS, Warltier DC, Kersten JR. N-acetylcysteine restores isoflurane-induced preconditioning against myocardial infarction during hyperglycemia. Anesthesiology. 2003;98:1384-90.

15. Yang Z, Day Y-J, Toufektsian M-C, Ramos SI, Marshall M, Wang XQ, et al. Infarct-sparing effect of A2A-adenosine receptor activation is due primarily to its action on lymphocytes. Circulation. 2005;111:2190-7.

16. Yang Z, Day Y-J, Toufektsian M-C, Xu Y, Ramos SI, Marshall MA, et al. Myocardial infarct-sparing effect of adenosine A2A receptor activation is due to its action on CD4+ T lymphocytes. Circulation. 2006;114:2056-64.

17. Schwarz ER, Somoano Y, Hale SL, Kloner RA. What is the required reperfusion period for assessment of myocardial infarct size using triphenyltetrazolium chloride staining in the rat? J Thromb Thrombolysis. 2000;10:181-7.

18. Capes SE, Hunt D, Malmberg K. Gerstein HC.Stress hyperglycaemia and increased risk of death after myocardial infarction in patients with and without diabetes: a systematic overview.[see comment]. Lancet. 2000;355:773-8.

19. Ishihara M, Kojima S, Sakamoto T, Asada Y, Tei C, Kimura K, et al. Acute hyperglycemia is associated with adverse outcome after acute myocardial infarction in the coronary intervention era. Am Heart J. 2005;150:814-20.

20. Webster KA. Stress hyperglycemia and enhanced sensitivity to myocardial infarction. Curr Hypertens Rep. 2008;10:78-84.

21. Hu Y, Block G, Norkus EP, Morrow JD, Dietrich M, Hudes M. Relations of glycemic index and glycemic load with plasma oxidative stress markers. Am J Clini Nutr. 2006;84:266-7; 70-6; quiz. 
22. Kawano H, Motoyama T, Hirashima O, Hirai N, Miyao Y, Sakamoto T, et al. Hyperglycemia rapidly suppresses flow-mediated endothelium-dependent vasodilation of brachial artery. J Am Coll Cardiol. 1999;34:146-54.

23. Mohanty P, Hamouda W, Garg R, Aljada A, Ghanim H, Dandona P. Glucose challenge stimulates reactive oxygen species (ROS) generation by leucocytes. J Clin Endocrinol Metab. 2000;85:2970-3.

24. Monnier L, Mas E, Ginet C, Michel F, Villon L, Cristol JP, et al. Activation of oxidative stress by acute glucose fluctuations compared with sustained chronic hyperglycemia in patients with type 2 diabetes. JAMA. 2006;295:1681-7.

25. Sudic D, Razmara M, Forslund M, Ji Q, Hjemdahl P, Li N. High glucose levels enhance platelet activation: involvement of multiple mechanisms. Br J Haematol. 2006;133:315-22.

26. Aljada A, Friedman J, Ghanim H, Mohanty P, Hofmeyer D, Chaudhuri A, et al. Glucose ingestion induces an increase in intranuclear nuclear factor kappaB, a fall in cellular inhibitor kappaB, and an increase in tumor necrosis factor alpha messenger RNA by mononuclear cells in healthy human subjects. Metabolism. 2006;55:1177-85.

27. Dhindsa S, Tripathy D, Mohanty P, Ghanim H, Syed T, Aljada A, et al. Differential effects of glucose and alcohol on reactive oxygen species generation and intranuclear nuclear factor-kappaB in mononuclear cells. Metabolism. 2004;53:330-4

28. Iwasaki Y, Kambayashi M, Asai M, Yoshida M, Nigawara T, Hashimoto K, et al. High glucose alone, as well as in combination with proinflammatory cytokines, stimulates nuclear factor kappa-B-mediated transcription in hepatocytes in vitro. J Diabetes Complications. 2007;21:56-62.

29. Zarich SW, Nesto RW. Implications and treatment of acute hyperglycemia in the setting of acute myocardial infarction. Circulation. 2007;115:e436-9.
30. Ximenes VF, Kanegae MP, Rissato SR, Galhiane MS. The oxidation of apocynin catalyzed by myeloperoxidase: proposal for NADPH oxidase inhibition. Arch Biochem Biophys. 2007;457:134-41

31. Horwitz LD, Kong Y, Robertson AD. Timing of treatment for myocardial reperfusion injury. J Cardiovasc Pharmacol. 1999;33:19-29.

32. Zhu X, Zuo L, Cardounel AJ, Zweier JL, He G. Characterization of in vivo tissue redox status, oxygenation, and formation of reactive oxygen species in postischemic myocardium. Antioxid Redox Signal. 2007;9:447-55.

33. Hoffmeyer MR, Jones SP, Ross CR, Sharp B, Grisham MB, Laroux FS, et al Myocardial ischemia/reperfusion injury in NADPH oxidase-deficient mice. Circ Res. 2000;87:812-7.

34. Johansen JS, Harris AK, Rychly DJ, Ergul A. Oxidative stress and the use of antioxidants in diabetes: linking basic science to clinical practice. Cardiovasc Diabetol. 2005;4:5.

35. Barbieri SS, Cavalca V, Eligini S, Brambilla M, Caiani A, Tremoli E, et al. Apocynin prevents cyclooxygenase 2 expression in human monocytes through NADPH oxidase and glutathione redox-dependent mechanisms. Free Radic Biol Med. 2004;37:156-65.

36. Johnson DK, Schillinger KJ, Kwait DM, Hughes CV, McNamara EJ, Ishmael F, et al. Inhibition of NADPH oxidase activation in endothelial cells by ortho-methoxy-substituted catechols. Endothelium. 2002;9:191-203.

37. Heumuller S, Wind S, Barbosa-Sicard E, Schmidt HH, Busse R, Schröder K, et al Apocynin is not an inhibitor of vascular NADPH oxidases but an antioxidant. Hypertension. 2008;51:211-7.

38. Stolk J, Hiltermann TJ, Dijkman JH, Verhoeven AJ. Characteristics of the inhibition of NADPH oxidase activation in neutrophils by apocynin, a methoxysubstituted catechol. Am J Respir Cell Mol Biol. 1994;11:95-102. 